\title{
Innovative engineering tools for clustering production
}

\author{
Dmitry L. Napolskikh ${ }^{1}$, Tatyana V. Yalyalieva ${ }^{2}$ \\ ${ }^{1}$ Candidate of Economic Sciences, Associate Professor of the Department of Management and Law \\ Volga State University of Technology, Russia, NapolskihDL@ yandex.ru \\ ${ }^{2}$ Candidate of Economic Sciences, Associate Professor of the Department of Management and Law \\ Volga State University of Technology, Russia, Yoshkar-Ola \\ NapolskihDL@yandex.ru
}

\begin{abstract}
The article deals with methodological problems of assessing the Innovative engineering tools for clustering production, the subject of the study is the potential of clustering. The author suggests method of assessing potential of clustering on the basis of the integral index (IILPC) and the private indexes innovative engineering tools for clustering production. The demographic situation is considered as a factor in the development of Innovative engineering tools for clustering production systems in the long term, the main trends and problems are highlighted. A list of indicators for characterizing the region's tools for clustering production market in terms of labor migration and labor market tensions was created, and an assessment of the labor tools for clustering production in the regions. Based on the values of the integral index of tools for clustering production potential of clustering, the author makes recommendations for implementation of state clustering production policy.
\end{abstract}

Key words :innovation, cluster, engineering clustering production.

\section{INTRODUCTION}

When analyzing the clustering processes of region's economy, the assessment of its tools for clustering production as a key factor of innovative development takes a fundamental place. One of the tasks of implementing cluster policy in Russian Federation is to increase labor productivity and quality reproduction of labor force. The regions of Volga Federal district as a whole are characterized by the following problems of increasing labor potential: reduction of labor resources due to negative demographic trends in General; unfavorable to most peripheral areas (including rural) migration, expressed in the outflow of labor resources, growth of interregional competition for qualified workforce and students.

The relevance of assessing the labor potential of the regions of the Volga Federal district is due, on the one hand, to its influence on the effectiveness of the processes of formation and development of innovative clusters, on the other hand, clustering processes have a significant impact on the labor market of the region, and, accordingly, its labor potential. The problem of optimizing the quality characteristics of the region's labor force remains relevant in the conditions of an innovative economy due to increased international competition in the markets of high-tech products and increased mobility of labor resources. The purpose of this work is to assess the labor potential of the economy of the Volga Federal district regions as a factor of economic clustering.

\section{RESEARCH METHODOLOGY}

The methodology for evaluating clustering processes and innovative development of the economy is based on the author's own developments, as well as the following set of approaches to the study of cluster formation and development: cluster model of M. Porter [7]; neoclassical cluster model; Ö. Sölvell network model of interaction between organizations participating in the cluster [9]; institutional model of the cluster of Ch. Ketels [3] and G. Lindquist [5]. Difficult for any single economy to incorporate and take advantage of the relevant technological advances in economy, as well as the underlying conditions in innovation [6].

As the most promising approaches to development of assessment of labor potential should highlight the qualitative analysis of natural and mechanical movement of labor resources at the regional level $[1,4]$, structural $[2,10]$ and quantitative assessment of labor potential of the region based on total fund of working time [11], integrated assessment of labor potential [8]. This study of the labor potential of the Volga Federal district regions is based on the method of integrated assessment, as the most appropriate to the tasks, since this method involves a quantitative assessment of labor potential, taking into account the influence of quality indicators based on the use of the index method [12,13,14].

In the developed method of integrated assessment of the labor potential of the region's economy clustering the following key elements are identified: the integral index of labor potential for clustering the region's economy (IILPC) and the partial indexes of labor potential that form integral index. Based on the relative indicators of the region's labor potential, the following indexes are proposed for calculating the integral index of labor potential for clustering:

-population reproduction index (IPR), equal to the value of the net population reproduction coefficient for the whole region; 
Dmitry L. Napolskikh et al., International Journal of Emerging Trends in Engineering Research, 8(9), September 2020, 4963 - 4966

-urbanization index (IUR), equal to the percentage of the region's employed population living in urban settlements;

-qualification index (IQU), equal to the share of highly qualified employees in the total number of qualified employees in the region;

-scientific personnel index (ISP), which is equal to the number of research and development personnel per 100,000 highly qualified employees in the region;

-labor migration index (ILM), equal to the difference between those entering other regions and those leaving for work in the region in relation to the total labor force in the region;

- potential labor force index (IPLF), equal to the combined share of the unemployed and potential labor force in the region;

-labor clustering index (ICL), which is equal to the share of the employed population of the region working in the organizations participating in the cluster.

Accordingly, the integrated index of labor potential for clustering the region's economy (IILPC) is calculated using the following formula:

IILPC $=\frac{I_{V R} \times k_{1}+I_{U R} \times k_{2}+I_{Q U} \times k_{3}+I_{5 P} \times k_{4}+I_{L M} \times k_{5}+I_{p L F} \times k_{6}+I_{C L} \times k_{7}}{\sum_{j=1}^{N} k_{i}}$

The coefficients $\mathrm{k} 1-\mathrm{k} 7$ determine the weight of indices when calculating the value of the integral index. The methodological advantage of the proposed methodology for analyzing labor potential is the possibility of a comprehensive assessment of the region's labor resources from the point of view of economic clustering problems. The overall demographic situation in the Volga macroregion. The overall demographic situation in the Volga macroregion. Considering the problems of clustering the economy of the Volga Federal district from the point of view of the labor potential, it is necessary to consider the demographic situation in the Volga macroregion. The study considers the dynamics of population changes in the regions of the Volga Federal district from 2010 to 2019. the results are shown in figure 1 .

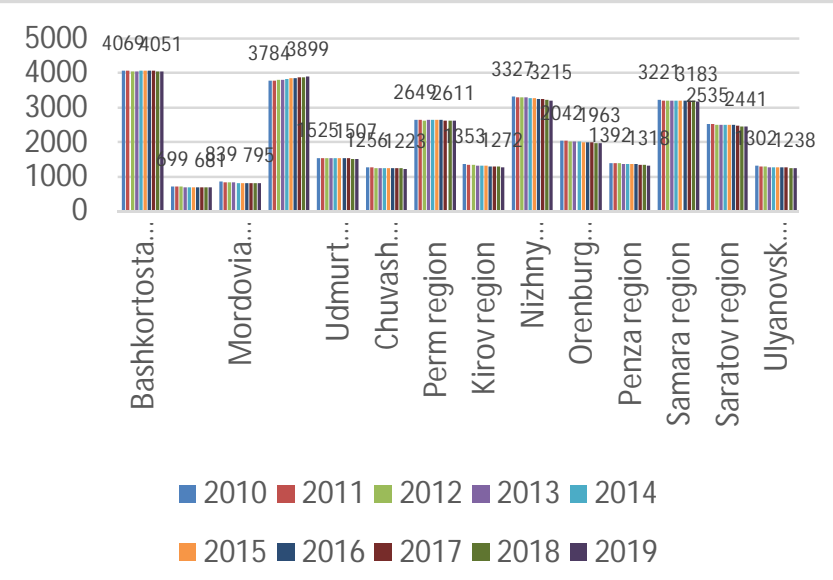

Figure 1: Population of regions of Volga Federal district in the years 2010-2019, thou. Persons

(Source: Federal state statistics service of the Russian Federation: https://www.gks.ru/folder/12781)
We note a clear trend towards population growth for the Tatarstan Republic, while for the other regions of the Volga macroregion there are negative trends in population decline. It should be noted that the leading positions in the Volga region in terms of the number of workers are taken by the republics Bashkortostan and Tatarstan, the Nizhny Novgorod, Samara and Saratov regions, as well as the Perm region. The republics Mari El and Mordovia have the least potential workforce. Figure 2 shows the value of the indicator "net population reproduction coefficient" for the regions of the Volga Federal district.

Note that the values of the net population reproduction coefficient are in the range from 0.6 to 0.8 , the lowest value in the Mordovia Republic. For all the regions considered, with the exception of the Tatarstan Republic, higher values of this indicator are observed for the rural population, especially for the republics of Bashkortostan, Udmurtia and Chuvashia, Perm, Kirov and Orenburg regions. Another important factor affecting the labor market and the overall demographic situation in the Volga macroregion is population migration, the total results of which for 2018 are shown in figure 3.

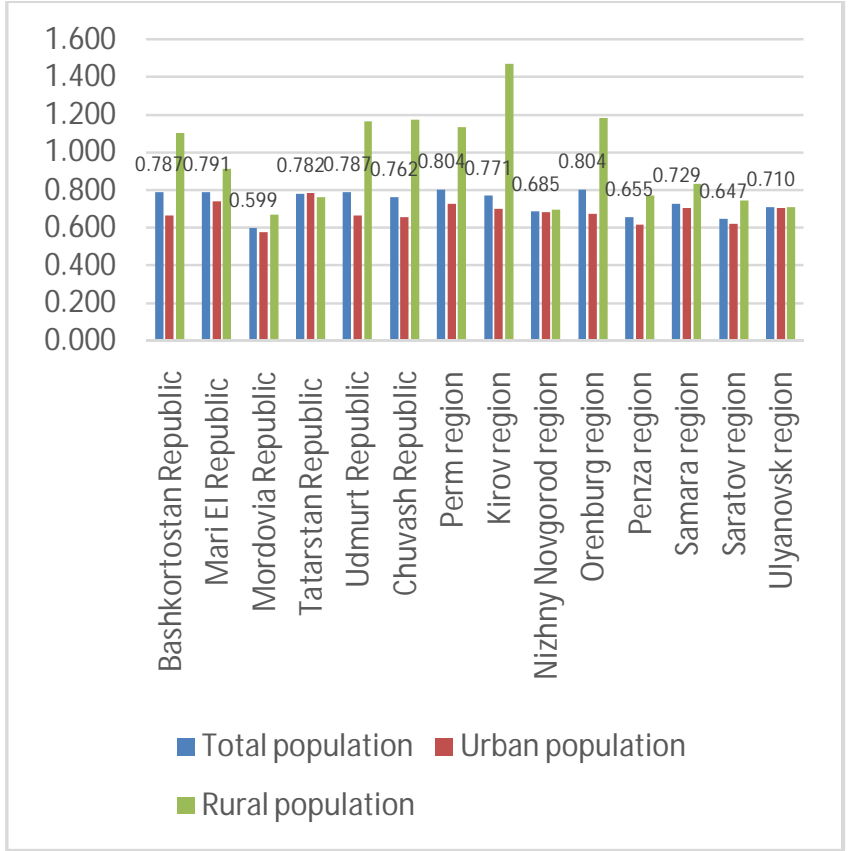

Figure 2: Net reproduction rate by regions of Volga Federal district in 2018 (Calculated based on data from the Federal state statistics service of the Russian Federation: https://www.gks.ru/folder/12781)

In general, among the regions of the Volga Federal district, only the of Tatarstan Republics characterized by a positive value of population migration, a number of regions (the Republic Mari El, Penza, Samara and Ulyanovsk regions), despite the positive value of migration exchange with foreign countries, have negative values of population changes due to migration. 
Dmitry L. Napolskikh et al., International Journal of Emerging Trends in Engineering Research, 8(9), September 2020, 4963 - 4966

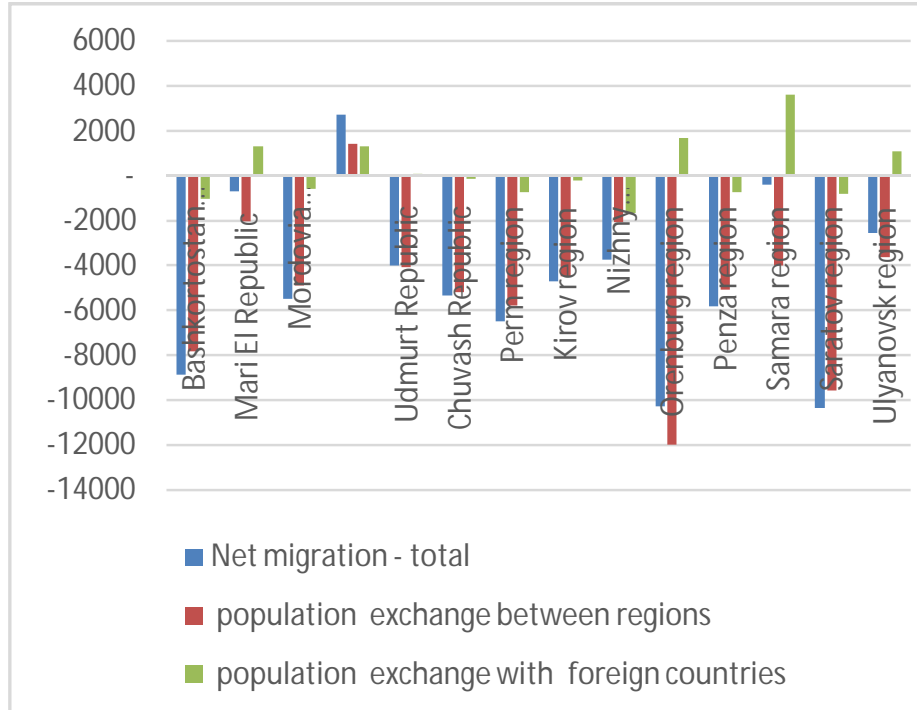

Figure 3: Total results of migration by regions of Volga

Federal district in 2018, persons (Source: Federal state statistics service of the Russian Federation: https://www.gks.ru/folder/12781)

One of the most effective models of integrated socio-economic development of territories in modern conditions is the clustering of production. Consider the level of influence of clustering processes on the labor market of the regions of the Volga Federal district. Successfully functioning clusters were formed on the territory of 10 of the 14 regions that are part of the Volga Federal district. Clustering processes do not cover the economic systems of the Mari El Republic, Kirov, Saratov and Orenburg regions. In half of the regions covered by clustering ( 5 out of 10 ), only one cluster is successfully functioning. Figure 10 shows the percentage of the employed population of the region working in organizations participating in clusters. Based on the above statistical data for 2018, we calculated the author's proposed integrated index of labor potential for clustering the economy of the Volga regions (IILPC).

\section{CONCLUSIONS}

In the course of the study of the demographic situation in the Volga region in the context of the problems of economic clustering is the main objective factor affecting the balance of socio-economic development of this macroregion, a significant differentiation of regions by population was revealed (the population of the Republic of Bashkortostan is 5.9 larger than the Republic of Mari El). This situation is exacerbated by the marked tendency to the decrease of population in all regions of the Volga Federal district with the exception of the Tatarstan Republic, ranked second in terms of population, and high proportion of pre-retirement and retirement age of the disabled population up to 15 years in the Republic of Mordovia, Kirov and Penza regions.

Another key factor that determines the prospects for the labor potential of the Volga region regions is insufficient population reproduction for balanced development, the values of the net population reproduction coefficient are in the range from 0.6 to 0.8 , while only the Tatarstan Republic is characterized by a positive value of both population migration as a whole and interregional labor migration. The main factor for people leaving for work in other regions is the difference in the average wage between the regions of the Volga region and in comparison with other regions of Russia, as well as high tension in the labor market. It is proposed to use the following indicators of tension in the labor market of the region: the unemployment rate $(\%)$, the average time of searching for work by the unemployed (months), the share of unemployed looking for work for 12 months or more (\%).

The analysis of the processes of clusterization of the Volga region economy revealed a significant differentiation of regions in terms of the effectiveness of cluster policy and the presence of successfully implemented cluster initiatives on the territory of the region. The leaders of the Volga region in the field of cluster development are the Tatarstan Republic, Perm, Samara, Penza and Ulyanovsk regions. The clustering processes do not cover the economic systems of the Mari El Republic, Kirov, Saratov and Orenburg regions.

The obtained values of the integral and private indexes of the labor potential of clustering the economy for the Volga region regions (IILPC) allowed us to draw the following conclusions. The Nizhny Novgorod region has the greatest potential for clustering the economy in terms of labor potential. At the same time, this potential remains largely unused, since the share of the employed population of the Volga regions working in the organizations participating in the cluster is $0.32 \%$. The first place of the Nizhny Novgorod region is due to the high values of private indices of urbanization (the largest agglomeration of the Volga region), skills and scientific personnel, and the Nizhny Novgorod region is characterized by a fairly stable situation of labor migration in comparison with other Volga regions.

The group of leading regions also includes the Perm region, Tatarstan Republic, Samara and Ulyanovsk regions, which are marked by high values of labor clustering for the Volga Federal district. The above-mentioned regions have significant labor potential for further development of production clustering processes based on market mechanisms, which should be taken into account when choosing forms and methods of state cluster policy. The following regions have the lowest value of the integral index (IILPC): Orenburg region, Chuvash Republic, Mari El Republic, and Mordovia. Implementation of the state cluster policy in these regions should include mechanisms of Federal support for the integration of production, education and science, as well as use the potential of interregional cooperation with the leading regions in the framework of joint cluster projects.

The obtained results allowed to formulate the following tasks in the study of processes of a clustering of economy of regions of the Volga region, namely, impact assessment of implementation of cluster policy in the development of regional innovation systems, and the impact on clustering of economic space of a region of the development process of urban agglomerations.

\section{ACKNOWLEDGMENTS}

This research was supported by grant of Russian foundation for basic research № 18-010-00647 a. 
Dmitry L. Napolskikh et al., International Journal of Emerging Trends in Engineering Research, 8(9), September 2020, 4963 - 4966

\section{REFERENCES}

1. M.Angelidou, ,C.Balla, A Manousaridou,., S.Marmeloudis, , \&D.Nalmpantis,. Spatial planning for urban resilience. assessing current prospects though a multilevel approach and a use case in northern greece. 2008

2. K. A.Gulin, A. A.Shabunova, E. A. Chekmareva. Labor potential of the region. 2009.ISERT RAS.

3. C.H. Ketels. Cluster policy: A guide to the state of the debate. In: Meusburger, P.Glückler, J., el Meskioui, M. (eds.) Knowledge and the economy, Publisher of Springer, Dordrecht, 2013, 249-269.

4. A.Kokkinou, ,G.Korres, , \&P.Dionysopoulou,. Investment in innovation and education: An efficiency benchmarking analysis in europe. Regional Science Inquiry, 10(3),2018, 147-152.

5. G.Lindqvist, Disentangling Clusters: Agglomeration and Proximity Effects. Publisher of EFI, Stockholm, 2009.

6. D.Napolskikh, T.Yalyalieva. Modeling of regional economic development based on innovative clusters. Regional Science Inquiry, 2019 11(2), 73-81.

7. M.E.Porter, C.H. Ketels, Clusters and industrial districts: Common roots, differentperspectives. In: Becattini, G., Bellandi, M., de Propis, L. (eds.) A handbook of industrial districts, Cheltenham, Edward Elgar,2009, 172-183.

8. N. M. Rimashevskaya. The methodology for determining the qualitative state of the population. Demography and sociology, 1993, 6, 7-21.

9. Ö. Sölvell. Clusters - Balancing Evolutionary and Constructive Forces. Ivory Tower Pub, Stockholm, 2009.

10. A. Vorobiev Labor potential of the regions of the Volga Federal district: analysis and opportunities for its improvement. Economy and entrepreneurship, 12 (part 2), 2015, 410-413.

11. E. V. Yalbacheva. Methods of calculation and problems of assessing the labor potential of the region. Bulletin of young scientists, from http://e-lib.gasu.ru/vmu/arhive/2004/01/72.shtml

12. . Ulbieva IS, Uzhakhov KM, Tsechoeva AH, Dzangieva AR, Uzhakhov MK. The construction technology of preschool institutions: Eco-friendly and fire-resistant materials. Int J Emerg Trends Eng Res [Internet]. 2020;8(4):1227-31

13. Gorshkova OO. Construction of long-distance oil pipelines. Int $\mathbf{J}$ Emerg Trends Eng Res [Internet]. 2020;8(1):60-6Kulikov I,

14. Karpukhin K. Studying energy efficiency of thermal management systems designed for electric vehicles with in-wheel motors. Int J Emerg Trends Eng Res [Internet]. 2020;8(6):2654-6 